\title{
LA CRÍTICA A LA EDAD. LOS RUBIOS DE ALBERTINA CARRI Y M DE NICOLÁS PRIVIDERA EN LOS DEBATES DE LA MEMORIA CONTEMPORÁNEOS
}

\section{CRITICISM OF AGE. ALBERTINA CARRI'S LOS RUBIOS AND NICOLÁS PRIVIDERA'S $M$ IN CONTEMPORARY DEBATES ABOUT MEMORY}

\author{
Carolina C. Bartalini \\ Universidad Nacional Arturo Jauretche, Argentina \\ CONICET \\ carolinabartalini@gmail.com
}

\begin{abstract}
Resumen:
A partir del estreno del primer documental de memoria de Albertina Carri, Los rubios (2003), irrumpe una nueva voz social y artística: la generación de lxs hijxs de desaparecidos por la última dictadura cívico-militar (1976-1983), cuya respuesta crítica no se hace esperar. El debate en torno a Los rubios -con intervenciones de las principales personalidades de la academia argentina a lo largo de toda la décadajunto con el debate en torno a lo individual y lo social en el primer documental de Nicolás Prividera, M (2007)-, exponen las aristas de los principales núcleos de discusión estético-política de esta época: las disputas estéticas entre autonomía y posautonomía del arte y las memorias en conflicto sobre el pasado reciente, que es también decir nuestro presente.
\end{abstract}

Palabras clave: memoria; debates críticos; hijos; valor; canon.

\begin{abstract}
:
From the premiere of Albertina Carri's first memory documentary, Los rubios (2003), a new social and artistic voice bursts in: the generation of daughters and sons of disappeared people by the last civil-military dictatorship (1976-1983). The debate around Los rubios - with interventions by the main personalities of the Argentine academy throughout the decade-together with the debate around the individual and the social in Nicolás Prividera's first documentary, M (2007)-, expose the edges of the main centers of aesthetic-political discussion of this era: the aesthetic disputes between autonomy and post-autonomy of art and the problem of memories in conflict over the recent past, which is also to say our present.
\end{abstract}

Kewwords: memory; critical debates; descendents; value; canon.

Recibido: 23 de septiembre de 2019

Aceptado: 25 de noviembre de 2019

\section{Introducción}

A lo largo de los años que siguieron a la reapertura democrática se han producido diferentes maneras de hablar sobre las experiencias de la violencia del 
genocidio de Estado de la última dictadura cívico-militar en cercano vínculo con los acontecimientos estéticos y políticos de cada coyuntura. En primera instancia, hubo dos zonas discursivas bien diferenciadas: el género testimonial y la ficción. Cada una con sus tradiciones, estilos, repertorios temáticos, procedimientos, circuitos de difusión y de lectura abordaron el pasado reciente $-\mathrm{o}$ incluso el mismo presente- de modos particulares y sensibles a las dificultades de dar cuenta de una de las más dolorosas y traumáticas escenas de la historia argentina en términos personales y comunitarios. Alrededor del 2001, momento disruptivo de los modos de pensar lo político y lo estético en términos de re-presentación, emerge una serie de producciones fílmicas, literarias y fotográficas de la generación de las hijas e hijos de militantes secuestradxs, asesinadxs, exiliados y/o desaparecidxs ${ }^{1}$ por la represión del Estado en la última dictadura cívico-militar (1976-1983) que logran articular el trabajo de la memoria con la exploración artística. Operando con el testimonio como elemento constitutivo y problemático para presentar y representar $^{2}$ una historia íntima y a la vez social, ponen en juego una dimensión especialmente significativa, la del lenguaje, para enunciar la experiencia de sí en relación con la experiencia de la generación que les dio la vida.

Son jóvenes que hablan en sus obras -en general primeras producciones- de sus experiencias como niñas y niños en los setenta y ubican en el mismo espacio donde se disponen los recuerdos la enunciación del yo actual para contribuir y reflexionar sobre los mecanismos de la memoria, la creación y los géneros canónicos, los modos de la construcción histórica, la voz y la subjetividad desde

1 Utilizaré la letra " $x$ " para referir a la dualidad y la simultaneidad de géneros de los sustantivos centrales de este trabajo: detenidxs-desaparecidxs, hijxs, niñxs, excepto cuando sea necesario resaltar el sentido femenino y/o masculino del término.

${ }^{2}$ En alemán, explica Gayatri Spivak en ¿Puede hablar el sujeto subalterno, hay dos palabras para referir a las ideas que en español están involucradas en el término "representar" y cuya observación nos permitirá afinar la reflexión sobre 2001 como momento de crisis de representaciones estético-políticas. Por un lado, darstellen refiere a la puesta en escena, a un retrato, la figura retórica, el arco que comprende la idea de figurar, la mímesis de acuerdo con Erich Auerbach. Por el otro, vertreten implica una idea de sustitución, del campo de la persuasión, que involucra el sentido de la representación política, del representante (Spivak 19-22). Podríamos traducir el primer término como re-presentar, confeccionar una imagen nueva a partir de una imagen dada (entendiendo que la imagen primera tampoco sea "la realidad", sino una figuración de ella), en tanto que el segundo está vinculado con los sentidos políticos del término representar, estar en lugar de otros, actuar como representante. Más acá de esta observación, en este trabajo evitaré utilizar este término por su ambigüedad semántica y, sobretodo como argumentaré luego, porque refiere a un objeto previo y dado que implica, en la tradición crítica, a un valor de lo "real" del que la obra "daría cuenta" con mayor o menor "precisión". Esta cuestión es uno de los puntos centrales que las producciones del corpus problematizan y, por tanto, me referiré a ellas en términos de "presentación" o "creación" de imágenes e imaginaciones sobre el presente, y su pasado. 
modalidades presentificadoras (Bartalini Experiencias, El cuerpo). Estas producciones del cine y la literatura proponen gestos que desarticulan y resignifican las identidades socialmente establecidas: hacen de la producción estética una experiencia colectiva que, también, discute qué implicancias comprende volverse un sujeto estético-político de la generación del 2001 (Bartalini Tradiciones).

Ubico 2001 como fecha inaugural de la serie debido a dos razones, una de orden estético y otra en el sentido político. Alrededor de 2001 (entre 1998 y 2002) se filmó Los rubios de Albertina Carri, película fundacional que se ha vuelto origen de una nueva tradición; en el año 2000 se presentó el documental de María Inés Roqué en México, Papá Iván, aunque aquí se dio a conocer años más tarde, e (h) historias cotidianas de Andrés Habegger. Alrededor de 2001 se organizaron estrategias de resistencia a la crisis económica que permeaba la sociedad bajo diversas modalidades de agenciamiento colectivo que tomaron la calle como espacio a disputar (movimientos piqueteros, de desocupados, ahorristas, organismos de derechos humanos, organizaciones sindicales, asambleas barriales, tomas de fábricas, desarrollo de comunidades artísticas alternativas, los casos de Eloísa Cartonera, Belleza y Felicidad, el Grupo de Arte Callejero y su ya célebre intervención urbana frente a la Casa Rosada "Liquidación por cierre", en julio de 2001, o el lanzamiento de 10.000 soldaditos de plástico en paracaídas desde un edificio del microcentro porteño el 19 de diciembre del 2001, entre otras). Por supuesto, me refiero a 2001 como una fecha entre, es decir, un momento que simboliza un tránsito entre proyectos estético-políticos e imaginarios sociales, que involucran continuidades y discontinuidades. Esta fecha es, naturalmente, una reducción semántica que excede ampliamente el estallido social de diciembre de ese año como respuesta a la crisis económica instaurada, cabe destacar, por las políticas económicas neoliberales de la dictadura.

Entre estas vivencias aparece la ausencia y las consecuencias presentes de lo que Pilar Calveiro ha analizado como "el poder desaparecedor", la hibridación del dispositivo concentracionario en el entramado social. Es una zona compleja y que cierta crítica ha dado en llamar "polémica" en tanto que nos enfrenta con un salto cualitativo en torno a los modos del trabajo con la memoria que expone, precisamente, su plural: las voces que hablan, que nos hablan, que nos atraviesan, las voces de las memorias con las que crecimos y convivimos, así como sus 
Artículo. Carolina C. Bartalini. "La crítica a la edad. Los Rubios de Albertina Carri y $M$ de Nicolás Prividera en los debates de la memoria contemporáneos".

ausencias y las necesidades de decir, de participar de la polifonía intrínseca de la memoria discursiva.

Como se ha dicho, el momento inicial se pronuncia con el estreno en el Festival de Cine Independiente de Buenos Aires, el 23 de abril de 2003, de la película Los rubios de Albertina Carri -aunque, como veremos, hubo producciones previas que venían ensayando estas líneas de hibridación genérica, especialmente la serie fotográfica de Lucila Quieto, Arqueología de la ausencia (1999-2001) y el mediometraje Papá Iván (2000) de María Inés Roqué-. Esta película, y la serie de prácticas estético-políticas que la continúan, desdiferencian (Ludmer) y cuestionan los límites entre los grandes géneros que organizaron la percepción y los pactos de lectura en el siglo XX: el testimonio, la ficción y la autobiografía se hibridan en exploraciones performáticas que proponen, necesariamente, nuevos modos de ver y leer.

La propuesta de estxs directorxs y escritorxs va más allá del trabajo de memoria y su problematización, así como supera en muchos aspectos ciertas lecturas que tratan de establecer referencias con la "realidad" en términos del género testimonial, "postmemoria", "realismo" o incluso que buscan en ellas claves de interpretación "históricas" sobre la dictadura. El gesto disruptivo de las producciones de lxs hijxs debe leerse en torno a los procedimientos estéticos que configuran, y que permiten considerarlas como partes de una serie singular en proliferación, en líneas de continuidad y discontinuidad con las tradiciones del cine y la literatura con las que dialogan, y discuten. ${ }^{3}$

En otras palabras, es preciso atender a los sujetos de enunciación y a los destinatarios creados por ellos, observar estas producciones como actos de apropiación de la lengua (de los lenguajes de cada género, de cada medio) donde lo que se juega es la voz, el estatuto de la voz pública en el discurso social y, por supuesto, sus condiciones de posibilidad y de legibilidad. De este modo, el primer interrogante que surge es ¿por qué la crítica literaria sería la primera en analizar /

\footnotetext{
${ }^{3}$ En este sentido, la nominación filiativa mediante la cual se ha referido a la generación de los "hijxs", como aquellxs que son en relación con sus padres, debe necesariamente ponerse en duda, y pensar modos de identificación de la serie que no lean solamente las producciones en relación a una categoría identitaria pre-existente -en vínculo filiativo con la generación previa- sino que también observe rasgos procedimentales, estéticos y políticos que las mismas producciones plantean. En este sentido, considero que el sintagma "generación del 2001" si bien cifra un colectivo mayor, involucra a la vez los rasgos centrales -temáticos, políticos y formales- del período, en el cual el pasado surge con la potencia de la revulsión del presente.
} 
cuestionar la irrupción de una película? La respuesta a esta pregunta, debe necesariamente ampliar el espectro y considerar, entonces, que ya desde el inicio Los rubios fue leída en el marco del discurso social sobre el pasado reciente y en fuerte contraste - para la época, insoportable- no solo generacional sino también de imágenes tanto de ausencia como de presencia.

\section{Voz y valor: el debate en torno a Los rubios}

El trabajo con los materiales que proponen estas exploraciones nos permite leer dos zonas superpuestas y porosas, por un lado, las relaciones peculiares que plantean entre el género testimonial y el relato autobiográfico, por el otro, el desfase entre las enunciaciones del cine y la literatura de la generación de lxs hijxs con respecto a las condiciones de legibilidad de su tiempo. El debate que continuó al estreno de Los rubios expone con claridad la segunda zona, una polémica en torno al estatuto de la re-presentación para dar cuenta del pasado reciente, la relación entre arte y política y, finalmente, las problemáticas de la enunciación y los géneros. Se podría caracterizar la serie retórica de este debate, cuyo eje es establecido por Martín Kohan y Beatriz Sarlo tempranamente, como la crítica a la edad porque involucró también la estigmatización del desafío en tanto categoría peyorativamente valorada como "adolescente", negando el papel provocador del gesto y postulando la actitud irreverente de Albertina Carri como "apolítica" y "superficial" (Kohan y Sarlo).

Me referiré en este escrito especialmente a las primeras intervenciones, la polémica que se dio entre los números 78 y 80 de Punto de Vista entre Martín Kohan y Cecilia Macón (2004), la publicación de Tiempo pasado de Beatriz Sarlo al año siguiente (2005) y la aparición de Otros mundos de Gonzalo Aguilar (2006), con un interesante capítulo dedicado a Los rubios. Así también las intervenciones de Daniel Link (2003) con respecto a Punto de Vista, y el análisis inaugural de la película y del campo de batalla discursivo que realiza María Moreno en el reportaje a Albertina Carri, "Esa rubia debilidad", publicado en el suplemento Radar de Página/12 a la semana siguiente del estreno (2003). Este debate continuó a lo largo de los años, con nuevas intervenciones de Ana Amado en su libro La imagen justa. Cine argentino y política (2009), el volumen Nuevo cine argentino de Jens Andermann (2015), el reciente análisis de Alejandra Oberti y Roberto 
Artículo. Carolina C. Bartalini. "La crítica a la edad. Los Rubios de Albertina Carri y $M$ de Nicolás Prividera en los debates de la memoria contemporáneos”.

Pittaluga en torno a la argumentación peyorativa de Sarlo hacia el dispositivo testimonial en (2016), entre otros.

Es fundamental, además, agregar a este debate, como haré en las próximas páginas, las intervenciones de la propia Albertina Carri en entrevistas y sobre todo en el volumen Los rubios. Cartografía de una película, editado en 2007, donde directa e indirectamente se refiere y responde algunas de las observaciones sobre su película; así como también la misma producción de Nicolás Prividera, $M$, que debe observarse como discurso interpelador y desafiante de este revuelo crítico (luego $M$, como veremos, generará otro debate en la revista de cine El amante).

Las primeras críticas negativas -las de Kohan y Sarlo- construyen un ethos discursivo que se posiciona en la figura del "adulto" que debe, desde cierta autoridad de la "propia vivencia" - paradójicamente trabajada por Sarlo-denunciar los desórdenes de la voz, la ambivalencia genérica, la ilegibilidad en términos de formatos esperables para "dar cuenta" de ese tema tan sensible y, como se desprende de sus argumentaciones, sólo posible de ser dicho por quienes vivieron la "experiencia límite" del secuestro y la desaparición. En este punto, la lectura de Sarlo es más controvertida, dado que culmina su capítulo sobre Los rubios señalando lo que antes había argumentado en torno al género testimonial como dispositivo inadecuado para el discurso de las ciencias sociales. Sarlo se detiene en el carácter inefable de la experiencia límite (que toma de Agamben, de Arendt y de Ricoeur) y, por lo tanto, cuestiona todo discurso testimonial, y, más aún las llamadas "escrituras del yo" como sesgadas, subjetivas y, entonces, carentes de valor documental para el ejercicio analítico de la memoria y de la Historia.

Dicho de otro modo, debemos leer estas lecturas críticas en un (des)tiempo, como un registro del desconcierto que la irrupción de Los rubios generó. En ellas se expone un desfase temporal y discursivo con el presente, una nocontemporaneidad en la forma que Giorgio Agamben imaginó (Contemporáneo) y que Daniel Link ha leído en torno al debate en Punto de Vista y el final de esta publicación:4 "la relación de contemporaneidad nos exige que nos coloquemos en

\footnotetext{
${ }^{4}$ Link publica en el suplemento Radar de Página/12, el 21 de septiembre de 2003, una entrevista a los integrantes del consejo de dirección de Punto de Vista, Hugo Vezzetti, Carlos Altamirano, Beatriz Sarlo, Adrián Gorelik e Hilda Sábato, donde se conversa, y discute, sobre las ideas de "cultura" y el papel de la publicación en el campo intelectual argentino. Este texto fue incluido junto con una reflexión sobre el fin de la publicación en Fantasmas. Imaginación y sociedad (410416). Punto de Vista se publicó entre 1978 y 2008.
} 
relación de escucha (y de silencio expectante) respecto de esa pregunta sombría que desencadena lo intempestivo" (Link Fantasmas 416).

¿Cuál fue la radicalidad del gesto que esta película propuso que habilitó lecturas tan distantes? Con plena lucidez, Carri anota en el guion de Los rubios, cartografía de una película (2007) que uno de los objetivos del filme fue "enfrentar al espectador con esta experiencia" en una película que pone "en escena la construcción de una ficción. Una búsqueda entre lo documental y lo ficcional, entre las imágenes propias y las de los otros -que nunca coinciden-, entre la fantasía y el deseo y el dolor de la pérdida. Un viaje en el que los márgenes se desdibujan y la niebla invade los espacios que visitaremos" (Carri 2007 23. El subrayado me pertenece). Así mismo, la directora evalúa la intervención -y la recepción- que la película propuso en aquella escena: "La película cumplió su objetivo: generó discordia, avivó el debate y se posicionó, generacionalmente, como una nueva voz" (Carri 10).

Vale la pena recordar que entre los polos del debate que sucedió al estreno de Los rubios se cifra el estatuto de la autonomía del arte, lo político y el discurso, en términos de institucionalización de la voz. Martín Kohan en "La apariencia celebrada" (Punto de vista, nro. 78, 2004), lee en la película de Albertina Carri la despolitización de un relato sobre la dictadura, una "pose frívola", un "tono indolente" y cuestiona la posibilidad de enunciación de esta generación -lo que Sarlo estaba leyendo en ese tiempo como relato de postmemoria-. Kohan acusa a Carri de hacer una película que no cumple con el "deber cívico de memoria" (Sarlo 141), dado que despolitizaría el relato sobre la violencia dictatorial: "las pelucas rubias -afirma- son, a la identidad, lo que Lo rubios es a la memoria, al pasado, a la historia: un juego de poses y un ensayo de levedad; donde las poses consiguen pasar por postura, y la levedad por gesto grave" (Kohan 30).

En otro ángulo, dos años después, Gonzalo Aguilar no duda en concluir que Los rubios ha sido la "película más política del corpus de los documentales sobre desaparecidos: no solo porque hace memoria, sino porque se plantea las posibilidades de hacer una comunidad con los signos del presente" (Aguilar 184). Acción, simulacro, desdiferenciación, identidad, memorias, comunidad: gesto. ¿Cuáles son los sentidos de lo político que se proponen en Los rubios y en las películas y literaturas que se abren luego de ella? Pero también: ¿cuáles son los sentidos de lo político -y del arte- desde donde son leídas? 
La noción de postmemoria fue acuñada por Marianne Hirsch (Family Frames) para el análisis de producciones artísticas de los hijos de los sobrevivientes del Holocausto. Esta categoría, que se adapta muy bien al caso europeo, presenta algunos problemas de rigurosidad con respecto al pasado reciente latinoamericano, específicamente, en torno a la violencia del terror de Estado de la dictadura cívicomilitar argentina y los relatos de la llamada generación de lxs hijxs. En primer lugar, la noción de postmemoria alude al trabajo textual con las memorias en segundo grado, diluyéndose la relación con el referente primario, el cual no es conocido sino a través de otros relatos contados por los padres, los sobrevivientes. Sin embargo, en torno a producciones de lxs hijxs no se produce ese pasaje de la memoria a la postmemoria, sino que son ellxs los que efectivamente vivieron en sus infancias violencias o recuerdan, con mayor o menor precisión por la edad que tenían en ese momento, las violencias contra sus padres. Más allá de esto, lo que predomina en todas estas producciones del cine y la literatura es el relato de la experiencia de haber crecido sin los padres, un tránsito subjetivo que, además, rechaza las categorías identitarias asignadas. No es tanto la hibridación semiótica de recuerdos, ni la impregnación empática de síntomas, como analiza Hirsch para el caso alemán, sino las propias vivencias de la ausencia.

Por otro lado, en esta jerarquización de recuerdos que la categoría de postmemoria plantea (los propios y los heredados, mediados por la palabra y el relato y, por lo tanto, mucho más inestables que los primeros), tal como señala Sarlo, se establecen niveles de fiabilidad y verdad a las enunciaciones y la problemática del testimonio asoma nuevamente. Considerar los relatos de lxs hijxs como escenas de postmemoria provoca que sus testimonios pierdan, efectivamente, cierto valor de veracidad e ingresen en el terreno de la imaginación, de la ficción.

Ahora bien, el problema de la argumentación de Sarlo es que Carri en Los rubios aborda justamente sus propias vivencias como niña que vive el secuestro de sus padres y trata de recordar el suyo propio, los tres días que estuvo ilegalmente detenida-desaparecida. Carri problematiza a través de diferentes procedimientos estéticos la complejidad del recuerdo atravesado por las voces de otros, personas cercanas, pero también por las voces las del discurso social que establece figuraciones acerca de cómo eran los militantes políticos, los desaparecidos, los padres. Al haber sido Albertina Carri testigo directa, Los rubios es, por tanto, una 
película que trabaja desde un referente primario - si se quiere seguir en esta lógicay que, precisamente pone en tensión la ontología de la memoria, y del olvido.

De acuerdo con Beatriz Sarlo, los sujetos nacidos en la década del setenta constituirían la generación de la postmemoria de la violencia institucional y social, ya que no habrían vivido de manera directa los hechos traumáticos que pretenden representar en sus producciones artísticas. Por lo cual, no estarían legitimados a brindar testimonio y construir significados legítimos para el discurso social establecido. Por el contrario, Ana Amado (La imagen justa) subraya que estos relatos exponen la memoria en su propia construcción, a través de la búsqueda de testimonios ajenos que interpelan al sujeto de la creación a la exploración introspectiva en su propio devenir, mostrando un tipo de relato que se distancia del criterio tradicional del documental-realista, a la vez que distorsiona los parámetros de la representación ficcional. Amado agrega que esta novedad no genera, como afirmaba Sarlo, un pérdida de relación con lo real -es decir, con la Historia y sus deberes de memoria-, sino que por el contrario la primera persona al potenciarse y exhibirse en el filme se muestra a sí misma en su propia construcción, en una configuración subjetiva y subjetivante que se desarrolla frente a la cámara, en un modelo propio de la técnica y la subjetividad contemporánea.

Carlos Gamerro establece que al analizar la serie de producciones cinematográficas y literarias de hijxs de desaparecidxs, la crítica ha caído solapadamente en asignar un referente previo a la obra con el cual el relato se relacionaba con mayor o menor cercanía. Es decir, lecturas en las que predomina la historia del espectador antes que la percepción del proyecto particular y su observación específica. Esta premisa de legibilidad es el pilar que sostiene la argumentación de Beatriz Sarlo en Tiempo pasado quien asigna a Los rubios, como a todo relato testimonial o autobiográfico, un estatuto de infiabilidad y una señal de peligro, en tanto que lo que le interesa es señalar la necesidad del "efecto de objetividad" para los estudios de la Historia. Sarlo parte de un academicismo acérrimo que se ve obturado, desde su perspectiva, en la complejidad del trabajo del arte con el testimonio.

Lo que Sarlo cuestiona es el énfasis en la subjetividad, indicando que detrás del discurso siempre hay "condiciones ideológicas que la sostienen", como si esta observación no le cupiera también a los estudios de las ciencias sociales. La memoria, entonces, se plantea como un deber: "el deber de la Argentina posterior 
a la dictadura militar [...] que hizo posible la condena al terrorismo de Estado" (Sarlo 129). Por el contrario, el arte, al perder esta funcionalidad cívica, sólo puede mostrar una experiencia particular en el terreno de la imaginería, en definitiva, nada confiable en términos históricos. De estas ideas se desprende la idea de "peligrosidad" que recorre el ensayo: la confusión entre "testimonio" e “imaginación”.

Esta dimensión polémica de las producciones de hijxs de desaparecidxs será reforzada y ampliada por los textos y películas posteriores que cuestionan dos aspectos del discurso social, y discuten nuevamente con este debate: ¿cuál es la historia que se debe contar?, y ¿cuál es la historia que se lee más allá de la proyecto particular? Tal vez sea necesaria -como plantea Nicolás Prividera acerca del debate sobre $M$ en El amante- "una cierta distancia para entender todo esto. Distancia temporal, en principio" (303)

La lectura trágica que realiza Beatriz Sarlo es muy cercana a la que se expresa en la carta que el Instituto Nacional de Cine y Artes Audiovisuales envía a la producción del filme para negar su apoyo económico. ${ }^{5}$ Carri decide montar este texto en el centro de la película y producir una puesta en escena de un debate grupal que impugna la decisión del INCAA. A la vez, en este gesto se cuestiona este tipo de lecturas deónticas que hacen uso de la retórica de la piedad para impugnar la emergencia de nuevas voces y rechazar cualquier corrimiento del eje de las "memorias de militancia" fuertemente presentes en el momento. El INCAA se posiciona en el lugar de la academia, como regulador de los discursos, pretende establecer las reglas. La carta manifiesta la "película necesaria" por una generación, la de los padres y madres desaparecidxs. Pero también la de los sobrevivientes e, incluso, la de muchos que en ese momento manejaban el poder institucional, como también es el caso de Beatriz Sarlo quien comienza Tiempo pasado mencionando su juventud en la década del setenta y la solicitud de una editorial, que ella negará, de contar sus memorias.

El centro del debate se plantea en torno al rol que deben desempeñar las entrevistas testimoniales y los usos que la película debe producir con ellos, quiénes deben hablar, y cuál debe ser el tono. Así lo señala la carta del INCAA:

\footnotetext{
${ }^{5}$ La carta de Instituto Nacional de Cine y Artes Audiovisuales (INCAA) está fechada el 30 de octubre de 2002 y se muestra en el centro de la película de Carri, para dar pie al posterior debate, en una escena clara de puesta en abismo.
} 
Creemos que este proyecto es valioso y pide -en este sentido- ser revisado con un mayor rigor documental. La historia, tal como está formulada, plantea el conflicto de ficcionalizar la propia experiencia cuando el dolor puede nublar la interpretación de hechos lacerantes. El reclamo de la protagonista por la ausencia de sus padres, si bien es el eje, requiere una búsqueda más exigente de testimonios propios, que se concretarían con la participación de los compañeros de sus padres, con afinidades y discrepancias. Roberto Carri y Ana María Caruso fueron dos intelectuales comprometidos en los 70, cuyo destino trágico merece que este trabajo se realice (El resaltado me pertenece).

En este enunciado queda claro que en aquel momento la necesidad de la institución estaba dada por la construcción de una historia total que, con similitudes y diferencias, lograra dar cuenta de un pasado reciente pero aún doloroso. Los testimonios se plantean como argumentos de autoridad, como casos o ejemplos que a modo de collage, y junto con la mirada atenta del analista social -como reclamaba Sarlo-, permitan configurar un relato propio de ser mostrado a las generaciones futuras.

Filiada a una larga tradición del cine documental político en Argentina, Los rubios dialoga con ella a través de la ruptura de los procedimientos clásicos del género: pone en práctica formas de la ficción para reescribir la serie y establecer que la diferencia entre el relato documental y el de la ficción no es de esencia sino de grado. Ana Amado analiza que el gesto de Albertina Carri consiste en disolver "la escena contemporánea del cine y de los relatos sobre el pasado", lo que ella llama la Historia: "en esta disolución el gesto de Albertina Carri no es romper con el pasado sino romper con las formas de romper con el pasado" (Amado 194). Los rubios polemiza con la figura del padre (padre cine-documental-testimonial, padre militante-política-Estado) para decir, por un lado, que ningún testimonio aislado, ni todo un arsenal de memorias testimoniales de compañerxs de militancia de los padres -como le reclama incorporar al filme el INCAA y como le exige Beatriz Sarlo para considerarla un registro testimonial- es suficiente para nombrar la ausencia que produjo su desaparición forzada en el plano íntimo, personal y colectivo; por otro lado, que es precisamente esa ausencia la que se quiere exhibir en la película. 
La apuesta de Los rubios, y lo que se sigue asociando la película al atributo "polémico", fue atreverse a mostrar los huecos de la voz, los silencios de las voces, todo lo que el testimonio dice sin decir. En este sentido, ubicar a Los rubios como una película testimonial podría ser un significativo avance en la reflexión sobre el tema, siempre y cuando observemos qué testimonia. El testimonio y el agenciamiento de la voz de una generación que debe lidiar con los fantasmas de la representación, pero elige, y exige, desplazar el eje del debate: del tema del enunciado al sujeto de la voz. Es en este corrimiento donde se actualiza nuevamente la dimensión performática del testimonio y de estas exploraciones fílmicas y literarias, en tanto que al remarcar lo accional, se señala lo no marcado de todo relato, su entramado, se advierten los riesgos de la construcción histórica como discurso total. Transformar la vivencia en experiencia a través de la producción artística no solo recompone las inflexiones de la voz, sino que también funciona como procedimiento vital y comunitario, y actualiza los debates por los sentidos y las memorias en disputa en el terreno del presente. Como ha dicho Walter Benjamin, "lo viviente sólo vence al vértigo del exterminio en el éxtasis de la procreación" (Benjamin 124).

\section{$M$ : el debate sobre el debate}

En otro debate acontecido unos años después, acerca de $M$, la ópera prima de Nicolás Prividera, estrenada en el año 2007, vuelve a aparecer el mismo argumento en torno a la relación entre lo individual y lo social. Gustavo Noriega, director de la revista de cine El amante, descalifica el documental por tender hacia una zona "personal" que se opondría a lo social, y que "obtura", como indicaba Sarlo, la comprensión del pasado. Sostiene Noriega: "hay que salir de lo personal para entender la historia" (33). ${ }^{6}$ Prividera responde, en el siguiente número de la

\footnotetext{
${ }^{6}$ La crítica de Gustavo Noriega salió publicada en el número 183 de la revista El amante, publicación medular sobre cine que nació en diciembre de 1991, pasó a la escena digital en diciembre de 2011, y finalmente dejó de publicarse a comienzos de 2017. Gustavo Noriega fue el director de El amante hasta su cierre; ahora tiene un programa en Radio Ciudad y escribe columnas sobre cine, política y derechos humanos en el diario La Nación. Polémicas han sido muchas de sus afirmaciones sobre las políticas recientes de derechos humanos, tanto desde la postura negacionista del discurso del poder actual, como para cuestionar a los organismos de derecho humanos y hasta la cifra de desaparecidxs. Noriega -junto con Hugo Vezzetti- defiende y justifica la peligrosa noción de "memoria completa" y ampara a los genocidas -y sus familiascomo víctimas de la "guerrilla". Sobre estos nuevos intereses, Noriega publicó en 2017 un volumen de revisión terminológica sobre palabras asociadas a la década del setenta, bajo el
} 
revista (184, septiembre de 2007) -luego reproducido en el libro escrito por el documentalista El país del cine: para una historia política del nuevo cine argentino (2014) - que, como es evidente, aquella afirmación, semejante lectura, parte de un supuesto equivocado dado que entiende "lo personal" como "lo individual".

El número 183 de El amante contó con la crítica de Eduardo Rojas sobre $M$, "Recordando con ira", y una nota especial de su director, Gustavo Noriega, sobre Los rubios y $M$ titulada "Lo que nos hacen", cuyo copete dice así: "Esta nota es una crítica en contra de varios aspectos de $M$ y, a la vez, una comparación con Los rubios y una puesta en perspectiva de los métodos de la película de Prividera y, probablemente, la continuación o el inicio de una polémica” (Rojas 32). Tanto Noriega como Eduardo Rojas hacen hincapié en la división entre lo "personal” y "lo político" - argumento que también sustenta, como vimos, la retórica de Punto de Vista-.Un dicotomía que, en palabras de Josefina Ludmer, es propia de la imaginación temporal del siglo pasado todavía acuciada por las distinciones absolutas que supieron dividir, para organizar, el mundo de lo real y lo imaginario: civilización y barbarie, campo y ciudad: mutatis mutandis, documental subjetivo y realismo histórico, el "pasado glorioso y el presente mezquino” (Aguilar 130).

Nicolás Prividera interviene en el debate en el número siguiente de $E l$ amante con un tono encolerizado por lo que él llama una argumentación que naturaliza la "anomia social". En su respuesta, expone un núcleo que ha sido el punto de quiebre de ciertas lecturas críticas - que más allá de disentir en cuanto a los criterios estéticos- han pretendido desautorizar, deslegitimar, y ubicar eternamente en el terreno de "lo nuevo" -y por tanto, críticamente descalificable por su propia ontología- a partir del "fantasma terrible" que significa hacerse cargo de lo personal como orden de lo social, que es decir lo subjetivo como parte y condición de lo político. ${ }^{7}$

En el mismo sentido presentado por Los rubios y $M$, Prividera observa frente al supuesto autoritarismo que Noriega le endilga por cuestionar los pactos de silencio sociales en torno a la militancia de los setenta y la represión genocida,

sensacionalista título de Diccionario crítico de los años 70. Todo lo que se dijo y lo que no se dijo de la época más violenta de la Argentina (Margen Izquierdo, 2017).

7 Prividera publica su respuesta en el siguiente número de El amante (184), donde discute especialmente las premisas de lectura de Noriega no solo con respecto a su película sino también en relación con la época aludida. Así mismo, señala que Noriega había "canonizado" en su revista a Los rubios, y que ahora "define como autoritario" el gesto de Prividera en su filme. 
cuyo motor es precisamente el gesto cuestionador y contestatario de $M-$, que "el verdadero autoritarismo es querer devolver esa violencia (social, sí) al desamparo del yo, y confinarla a la soledad del confesionario" (2014: 303).

"A medida que nos alejamos de los años terribles -analizan Alejandra Oberti y Roberto Pittaluga- el territorio de las luchas por el sentido de lo sucedido se traslada al plano de las memorias" (40). Los rubios, al centrarse en la dimensión de confección - de la película, de la memoria- establece un objetivo radicalmente diferente al solicitado por el INCAA: lejos de la exhibición de un relato cerrado se focaliza en señalar los huecos, la zona ambigua, contradictoria y confusa de las memorias, recuperar lo no dicho de las palabras, reflexionar sobre la imposibilidad de narrar, e incluso, sus peligros. Por su parte, $M$, tiempo después, sale en la contraofensiva.

Nicolás Prividera cuestiona, por un lado, el rechazo de Carri a la Historia en la línea de Kohan y Sarlo (cfr. Prividera en Kairuz)-, y por el otro, extiende la discusión de la generación de sus padres en sus militancias al presente de las líneas temáticas que cada uno tomó en sus aproximaciones fílmicas. En este último aspecto, como parte de un debate mayor -encontrado con las discusiones de los testimoniales de militancia y de HIJOS- Prividera apuntó también a la estética cuestionadora del género que propuso Carri, aún más tarde le reconociera los modelos procedimentales que tomó de Los rubios para la confección de $M$. Dice Prividera en una entrevista realizada por Mariano Kairuz: ${ }^{8}$

[...] si Albertina no intenta articular esa historia es porque ya la tiene, porque sus padres eran militantes conocidos, y ella creció en un medio en el que esta historia siempre estuvo a mano. En su película aparecen testimonios que ella ha escuchado mil veces, y el hartazgo que muestra es comprensible; es un casete que ella intenta romper.

Albertina Carri, por su parte, viene señalando -por ejemplo en la entrevista de María Moreno, "El libro de ésta", de marzo de 2007-que las decisiones estéticas están naturalmente condicionadas por las líneas de vida, y que por lo tanto, Los rubios tampoco pretende ser un modelo ejemplar, sino una exploración vital y subjetiva sobre la memoria y su propia historia. Más allá de estas cuestiones de

\footnotetext{
${ }^{8}$ La entrevista fue realizada por Mariano Kairuz a Nicolás Prividera y se publicó como nota de tapa en Radar, Página/12, el 18 de marzo de 2007.
} 
índole más sensible que estéticas, Nicolás Prividera reconoce tempranamente (y luego profundizará en esto en El país del cine, 2014) que su visión de Los rubios le "generó un gran impacto" dado que "lo que aparecía centralmente en Los rubios era la posibilidad de armar una historia con restos; aunque sea la historia de la dificultad de articular una historia" (Prividera en Kairuz).

En este último sentido, el debate que Prividera entabla en el libro en el que revisa la historia del cine político en Argentina -El país del cine. Para una historia política del nuevo cine argentino- con Gustavo Noriega y Eduardo Rojas, vuelve al punto inicial de esta argumentación: la potente relación entre lo personal y lo colectivo que ambos, Carri y Prividera, llevan adelante en sus indagaciones fílmicas. Lo que a primera vista podría parecer un gesto acusatorio factible de ser interpretado, incluso, como un cuestionamiento estxs directorxs a las militancias de los padres, resulta, si se afina la mirada, una observación más sutil y urgente a los tiempos de sus actualidades: un interrogante revulsivo $-\mathrm{y}$, en este punto, sí profusamente polémico y político- a un entramado social que ha hecho del silencio y la negación su arma de batalla.

Considerando este aspecto, es más entendible que Nicolás Prividera retorne a un análisis de Los rubios en su libro, puesto que lo hace para responder a las lecturas reaccionarias de Noriega y Rojas. Ambos críticos, -como antes hiciera Sarlo- parecen pretender que lo personal se mantenga separado de lo social, como si estas películas no estuvieran diciendo a los gritos todo lo contrario, y demostrando en su hacer su artificiosidad. Se produce en estas críticas un sentido de lo "personal" en términos de "individual, alejado de lo colectivo. Por el contrario, las producciones de Carri y Prividera -así como todo el entramado de memorias posautónomas de lxs hijxs- plantean que no es posible escindir lo personal de lo político y que esto es, siguiendo a Hanna Arendt, precisamente el agenciamiento de lo común, el entre-nos: "la política nace en el entre-los-hombres, por lo tanto completamente fuera del hombre; la política surge en el entre y se establece como relación" (Arendt 46). En esta línea, el gesto que producen es estético y es político en tanto que recuperan el sentido comunitario de lo político como forma de afección personal-social que tenían, también, sus padres como militantes en las décadas del sesenta y setenta. 
El decidido didactismo retórico que Nicolás Prividera configura en $M$ demuestra que -más acá de Los rubios y del debate que media entre estas dos películas- en su momento de enunciación había una zona de las acciones llevadas a cabo durante la dictadura que -al parecer del director- seguía sin percibirse. En otras palabras, Prividera elige la omisión de las críticas a la militancia -tema ya, por cierto, bastante abordado a esa fecha- para desplazar el foco de la discusión: " $M$ nunca criticó la militancia per se o en abstracto, sino a una sumisión acrítica que derivó en plegarse a una conducción verticalista que hace rato había perdido el rumbo" (Prividera El país). En esta línea, podemos afirmar que Los rubios tampoco se funda en la crítica a los padres -como suelen plantear las lecturas de la "generación de los padres"-, sino que se cuestionan las decisiones personalespolíticas de una generación que incluye especialmente a sus verdugos y cómplices. ${ }^{9}$

Los gestos que Carri y Prividera proponen, exponen las posiciones enunciativas donde artistas y críticos deciden posicionarse. El gesto de Prividera, como veremos luego, apunta a la queja, al enojo. Pero no es un enojo con la madre, como fue leído erróneamente; por el contrario, hay profusión de afecto para ella. Así como tampoco es un enojo dirigido hacia "la militancia a secas" -como es claro para cualquiera que atienda al filme-, sino al presente, a la sociedad actual. Los sobrevivientes no son cuestionados por "haberse salvado" -como se plantea en el discurso más duro de las memorias de militancia de la década del noventa, bajo la figura del "traidor" - sino que la crítica se realiza por el callar, por el sometimiento al silencio -que Prividera lee como complicidad-, lo que Pilar Calveiro observa en Poder y desaparición como las técnicas silenciadoras del poder concentracionario sobre el cuerpo social.

Ahora bien, la pesquisa que lleva a cabo Prividera en $M$ es para él y su familia, para su filme, y para el estatuto de lo actual, absolutamente necesaria. En

\footnotetext{
9 Albertina Carri modificará sus tesis sobre la memoria en los años que van de Los rubios a Cuatreros, su último documental estrenado en 2016. Puesto que si en Los rubios hay una retórica que señala los matices de la memoria como ficción, como montaje artificial que debe deconstruirse, en Cuatreros se percibe una apuesta hacia la memoria como archivo, tanto en el sentido foucaultiano de la voz como en el significado material del término. La memoria -parece subrayar Carri en sus últimas intervenciones-, conforme pasan los años y nos alejamos de los años setenta, necesita además del testimonio del documento. Así mismo, Cuatreros plantea una línea hacia el futuro muy enfática: la maternidad y el legado de los padres se vuelve a poner en cuestión atravesado por la propia experiencia de la directora con su hijo, tal como concluye la película en sus palabras finales.
} 
la película escasean los datos sobre el secuestro de su madre, sobre su militancia previa, menos aún es posible encontrar referencias a su cautiverio, asesinato y desaparición. Esto es lo que Prividera señala, busca y reclama a la Justicia, a los Organismos de Derechos Humanos, y a los perpetradores que siguen eligiendo callar. La frase efectista que Prividera enunció en la entrevista de Mariano Kairuz -sobre las diferencias entre los altos mandos y los "perejiles", palabra que aparece, por cierto, varias veces en $M-$, ha sido extrapolada en otras diversas lecturas que la señalan como un cuestionamiento del director a la película de Carri, en una retórica que pretende usarla como argumento de las premisas peyorativas de las líneas críticas hacia Los rubios que ya he comentado.

Considero, por el contrario, que la observación de Prividera apunta a otra cuestión, la diferencia formal de ambas películas dadas las condiciones de sus inicios y trayectos. Mientras que en Los rubios es posible problematizar los mecanismos de la memoria porque hubo recuerdos y discursos encontrados sobre los padres, en $M$ lo que falta es precisamente eso - no hay información sobre lo que pasó con la madre luego de su secuestro, como tampoco sobre sus relaciones directas con las organizaciones insurgentes de los setenta-; por lo tanto, el filme se plantea como una investigación, la investigación que el Estado no había hecho para reparar, al menos mínimamente, el daño causado a sus víctimas.

El trabajo de la memoria que lleva a cabo Prividera necesita de una exploración que, en términos personales y colectivos -por tanto, políticos-, recupere, eche un poco de luz, sobre todo aquello que la sociedad sigue todavía manteniendo en el silencio. Por tanto, cuestionar ese trabajo -más allá de las afinidades o reticencias estéticas que el filme pueda generar-, significa estar mirando otra cosa, otra película, en otro tiempo. Explica Prividera el flujo de $M$ :

[...] en mi caso particular yo no tenía estos testimonios; era lo que tenía que reconstruir y mi postura tenía que ser otra. El caso de mi madre es el de muchos de los llamados 'perejiles', los militantes de base, mucho más ambiguos e ignorados en todo sentido, pública y privadamente. Son historias mucho menos claras" (Prividera en Kairuz).

El gesto se propone como una reparación, una auto-exploración que pueda ser a la vez ejemplo de otras tantas vidas en situaciones similares. Aunque ciertas lecturas hayan pretendido hacer discutir a los ausentes a través de las posiciones de 
Artículo. Carolina C. Bartalini. "La crítica a la edad. Los Rubios de Albertina Carri y $M$ de Nicolás Prividera en los debates de la memoria contemporáneos”.

sus hijxs, considero que, salvando las distancias estéticas -que, lo sabemos, son políticas-, hay una misma necesidad y una interpelación similar en ambos filmes que traen al presente el tema y lo desplazan de sus enunciaciones previas.

\section{Conclusiones}

En este escrito he procurado recorrer ciertas aristas de los dos principales debates que se dieron en la crítica literaria y cinematográfica de las últimas décadas en torno a la vinculación entre arte y memoria. En las argumentaciones negativas, se observa cómo tanto Los rubios como $M$ no han sido leídas en su propio tiempo, sino que se las consideró, en primera instancia, desde marcos de legibilidad previos. Más allá de sus diferencias, es claro que ambas películas han desacomodado la escena en torno a los debates sobre le pasado reciente en la Argentina y los modos en que el arte se vincula con lo político. Leyendo las críticas a contrapelo es posible observar que en el desconcierto de Kohan o en el rechazo de Sarlo, así como en la incomodidad de Noriega, se cifra el estatuto de lo nuevo.

En los regímenes de exclusión que operan como "policía discursiva" (Foucault) de lo enunciable y lo visible, el archivo encuentra un contraluz, la huella de lo no dicho en lo que efectivamente ha sido enunciado, tal como señala Giorgio Agamben con respecto al testimonio: "el fragmento de memoria que queda olvidado en cada momento en el acto de decir yo" (Lo que queda 150). Las producciones multimediales y performáticas de las hijas ponen en tensión, y en nueva y prolífica discusión, formulaciones sobre nuestro presente y sobre el pasado a partir de la impregnación de los tiempos, de los lenguajes, de los ordenamientos del saber. Es preciso, intentar entonces, atender a sus gestos, a las naturalezas de sus producciones, desde el idioma que construyen. Un sistema que requiere de posicionamientos no solo estéticos, sino también éticos.

Estas películas muestran una y otra vez la imposibilidad de recuperar la ausencia así como la urgencia por intervenir en el presente mostrando el gesto, exponiendo incluso los temas que tanto escozor provocan en determinados círculos del "progresismo" estético y político. Por el contrario, sus primeras respuestas críticas exhiben lecturas desfasadas en el tiempo, esperando un discurso propio de las décadas anteriores y cuestionando la enunciación de un sujeto estético-político 
con una voz novedosa y disruptiva. Estos cuestionamientos aportan interesantes oportunidades para revisar los modos en que opera la crítica y las tiranías del canon. En definitiva: un debate sobre el lenguaje que no es más que decir: un debate sobre el poder.

\section{Bibliografías}

Agamben, Giorgio. “¿Qué es lo contemporáneo?” Desnudez. Trad. M. Ruvituso y M. T. D’Mesa. Buenos Aires Argentina: Adriana Hidalgo, 2014 [2006]). 17-29.

Agamben, Giorgio. Lo que queda de Auschwitz. El archivo y el testigo. Homo Sacer III. Trad. A. Cuspinera. Barcelona: Pre-textos, 2010 [2000].

Aguilar, Gonzalo. Otros mundos. Un ensayo sobre el nuevo cine argentino. Buenos Aires, Argentina: Santiago Arcos, 2006.

Aguilar, Gonzalo. Más allá del pueblo: Imágenes, indicios y políticas del cine. Buenos Aires, Argentina: FCE, 2015.

Amado, Ana. La imagen justa. Cine argentino y política (1980-2007). Buenos Aires, Argentina: Colihue, 2009.

Andermann, Jens. Nuevo cine argentino. Trad. F. Rodríguez. Buenos Aires,Argentina: Paidós, 2015.

Arendt, Hanna. ¿Qué es la política? (Trad. R. Sala Carbó). Buenos Aires: Paidós, 2009.

Auerbach, Erich. Mímesis. La representación de la realidad en la literatura occidental Trad. J. Villanueva y E. Ímaz. México: Fondo de Cultura Económica, 1996 [1942].

Bartalini, Carolina. "Experiencias de memoria, memorias de experiencias. Prácticas testimoniales del yo contemporáneas en el cine y la literatura argentina”. Tesis de Maestría en Estudios Literarios Latinoamericanos, Universidad Nacional de Tres de febrero, Argentina, 2018a.

Bartalini, Carolina. "El poema como mantra. Los huecos de la voz en El sexo de las piedras de Fernando Araldi Oesterheld". CHUY. Revista de estudios literarios latinoamericanos 5 (2018b): 175-193. http://www.revistasuntref.com.ar/index.php/chuy/article/view/185/193

Bartalini, Carolina. "La carta al padre. Intermedialidad y afiliaciones estético-políticas en el entramado de Cómo enterrar a un padre desaparecido de Sebastián Hacher". Exlibris 6 (2018c): 139-155. http://revistas.filo.uba.ar/index.php/exlibris/article/view/3113/0

Bartalini, Carolina. "Tradiciones y rupturas entre 2001. Una reflexión en torno a las tensiones del testimonio como performatividad estético-política en Los rubios de Albertina Carri”. Construir sobre los escombros. Política y cultura en la Argentina post-crisis 2001. Comps. Julián Delgado y Mauricio Schuttenberg. Florencio Varela: Editorial UNAJ, 2018d.

Bartalini. Carolina. "El cuerpo de la voz. Las producciones artísticas de las hijas e hijos de detenidos desaparecidos en la escena contemporánea". Zeszyty Naukowe, (Cuadernos científicos). Varsovia: Wszechnicy Polskiej, 2019.

Benjamin, Walter. Calle de mano única. Ed. y pról. Jorge Monteleone, trad. Ariel Magnus). Buenos Aires, Argentina: El cuenco de plata, 2014 [1928]. 
Carri, Albertina. Los rubios (documental, 89 min.). Argentina-USA: A. Carri y B. Ellsworth. Dirección y guion: Albertina Carri. Montaje: Alejandra Almirón. Fotografía: Carmen Torres y Albertina Carri. Sonido: Jésica Suárez. Actúa: Analía Couceyro, 2003.

Carri, Albertina. Los rubios: cartografía de una película. Buenos Aires, Argentina: Ediciones discusión, 2007.

Foucault, Michel. El orden del discurso. Trad. A. González Troyano. Buenos Aires, Argentina: Tusquets, 2012 [1970].

Gamerro, Carlos. "Memoria sin recuerdos". Facundo o Martín Fierro. Los libros que inventaron la Argentina. Buenos Aires, Argentina: Sudamericana, 2015. 489523.

Hirsch, Marianne. Family Frames. Photography, Narrative and Postmemory. Cambridge: Harvard University, 1997.

Kairuz,, Mariano. "La pesquisa. Entrevista a Nicolás Prividera". Página 12, Radar. Argentina. 18 de marzo de 2007.

Kohan, Martín. "La apariencia celebrada”. Punto de vista 78 (2004). 24-30.

Kohan, Martín. "Una crítica en general y una película en particular". Punto de Vista 80 (2004b). 47-48.

Link, Daniel. "Campo intelectual". Página12, Radar. Argentina. 21 de diciembre de 2003.

Link, Daniel. Fantasmas. Imaginación y Sociedad. Buenos Aires, Argentina: Eterna Cadencia, 2009.

Link, Daniel. "Archivos: ondas de memoria". Perfil. Argentina. 25 de septiembre de 2010.

Macón, Cecilia. "Los Rubios o del trauma como presencia”. Punto de Vista 80 (2004). 44-47.

Moreno, María. "Esa rubia debilidad. Entrevista a Albertina Carri". Página 12, Radar.19 de octubre de 2003.

Moreno, María. "El libro de ésta". Página 12, Radar. Argentina. 23 de marzo de 2007.

Noriega, Gustavo. Estudio Crítico sobre Los Rubios. Buenos Aires, Argentina: Editorial Pic Nic, 2009.

Noriega, Gustavo. “Lo que nos hacen”. El amante 183 (2007). 33-35.

Prividera, Nicolás. M. Documental, 143 min. Dirección y guión: Nicolás Prividera. Producción: Nicolás Prividera, Pablo Ratto, Vanessa Ragone. Argentina, 2007a.

Prividera, Nicolás, M. Lo que hacemos con lo que nos han hecho". El amante 184 (2007b). 38-39.

Prividera, Nicolás, M. Plan de evasión. (Texto leído en la presentación de Los topos de Félix Bruzzone) Argentina, 20 de mayo de 2009.

Prividera, Nicolás, M. El país del cine. Para una historia política del nuevo cine argentino. Buenos Aires, Argentina: Los Ríos, 2014.

Rojas, Eduardo. "Recordando con ira". El amante 183 (2007): 32.

Sarlo, Beatriz. Tiempo pasado. Cultura de la memoria y giro subjetivo. Una discusión. Buenos Aires, Argentina: Siglo XXI, 2005.

Spivak, Gayatri. ¿Puede hablar el subalterno? Trad. J. Amícola. Ed.-Apo. M. Topuzian. Buenos Aires, Argentina: El cuenco de plata, 2011 [1985]. 